\title{
Innovative health and safety standards is a sustainable development performance for the construction sector of Uzbekistan
}

\author{
Takhir Sultanov ${ }^{1 *}$, Ravshan Nurimbetov ${ }^{2}$ and Azizbek Zikriyoev ${ }^{2}$ \\ ${ }^{1}$ Department of Theoretical and Constructional Mechanics, Tashkent Institute of Irrigation and \\ Agricultural Mechanization Engineers, Kori Niyoziy str., 39, Tashkent, 100000, Uzbekistan \\ ${ }^{2}$ Tashkent Institute of Architecture and Construction, Navoi str., 13, Tashkent, 100011, Uzbekistan
}

\begin{abstract}
Due to high level of agglomeration many innovative standards are being implemented in industry sectors of the world countries. Ensuring the safety of the environment and the human production is an urgent task of modern civilized societies. Especially, it plays a great role in construction industry since many building processes become based on hitechnologies and extreme engineering atmosphere. Naturally, high probability of risks and hazard might cause in and out of the construction site during the working hours occur major accidents. Only way is reaming optimize and implement of international standards on Health and Safety Law at work affects human, financial and environmental factors of the country. The main objective purpose of the paper is reducing injures and accidents at construction industry and implement recent modern legislation system in Uzbekistan. It helps for contribute finishing construction projects on time, on budget and on high quality standards with zero rate accident regulation. Although, health and safety theories are important for the prevention of accidents scientifically with a little in-depth knowledge on their outcomes and processes. This research deals with this gap by using methodology on occupational safety standards in construction sites.
\end{abstract}

\section{Introduction}

In the last few years there has been a growing interest in context of scientific and technological development and rapidly growing industrial production sector. Introduction of new technologies and growing role of human beings in manufacturing process, social significance of health and safety working conditions of life are particular importance and more relevance for today. The issue of safety at work is particularly relevant in Uzbekistan as well. Under conditions that do not comply with legal requirements for a new standards such as: site induction, good organized welfare, environmental protection, accident prevention, hazard and risks, management of health and safety at work regulations; moral, legal and financial arguments for health and safety management; promoting a positive health and safety culture; risk assessment; principles of control; working at height - hazards and control; movement of people and vehicles - hazards and control; work equipment hazards and control; manual and mechanical handling hazards and control; electrical

\footnotetext{
* Corresponding author: tohir-zs@mail.ru
} 
hazards and control; fire hazards and control; chemical and biological health hazards and control; incident investigation, recording and reporting; dust removal, gas pollution, noise, vibration, and other factors of production affect millions of people at workstation [1].

New approaches for building sectors require highly qualified workers and law regulation. Health and safety are widely recognized as an important component of any organization. It is not only important to protect people from harm, but also to grow and indirect costs for accidents. These costs have dramatically increased retail prices with significant amount of funds has been spent in recent years, as the number of civil claims and rewards has been rising every year. It is important that all organizations understand the basic legal and regulatory requirements in the field of health and safety. Safety enforcement is usually only when all risks managed effectively for detection and reduction at site [2].

Construction of buildings is growing in big cities, where large and medium-sized companies are working as primary and subcontractors in Uzbekistan at the moment. However, these projects suffer fatal accidents, major injures and near misses as security measures are not strictly enforced. Therefore, this article presents a research structure for improving modern health and safety standards in the construction sector in Uzbekistan. From this point of view evaluation of training that monitors and supports quality delivery standards and transferability of the learning into the workplace are relevant.

\section{Methods}

This paper is a brief and short review of existing research studies, technical approaches of the world construction health and safety standards. According to the given question research strategy consists of ground theory, current status of national safety integration with comparative analysis with the UK standards and appropriate statistical analysis.

\section{Material}

The purpose of this article is to introduce basics on which health and safety are appropriate systems can be organized at workstation. Analyzing various methods Occupational Health and Safety standards for reducing accidents at construction sites such as even with the different qualified engineers (electrical, mechanical and civil), architectures, builders, managers, instructors and laborers.

New development program of Action of Strategy by 2017-2021 in Uzbekistan is designated huge reforms almost all sphere. Implementation of innovations in economic sectors such as industry plays major role with the $33.7 \%$ of the total GDP [3]. In particular, the "Obod Qishloq" and "Obod mahalla" programs were welcomed with great pleasure. This year, 3 trillion sums have been allocated for the construction and improvement works. As a result, 416 villages have a new look over the country [4]. Especially, construction sector must be organized well developed working conditions to minimize accidents workers safety concerns, legal cases and prosecutions, judicial review processes, are drawing the attention of government.

Nowadays it is not surprising that major part of operation costs are consumed by safety and accident ratios in the world. According to the UK's Health and Safety Executive believe its mission is to ensure that the risks to health and safety of workers are properly controlled (Fig.1). In terms of corporate responsibility, they are working to encourage organizations to:

$\checkmark$ improve management systems to reduce injuries and ill health;

$\checkmark$ demonstrate the importance of health and safety issues at board level;

$\checkmark$ report publicly on health and safety issues within their organization, including their 
performance against targets.

The HSE believe that effective management of health and safety:

$\checkmark$ is vital to employee well-being;

$\checkmark$ has a role to play in enhancing the reputation of businesses and helping them achieve high-performance teams;

$\checkmark$ is financially beneficial to business [5].

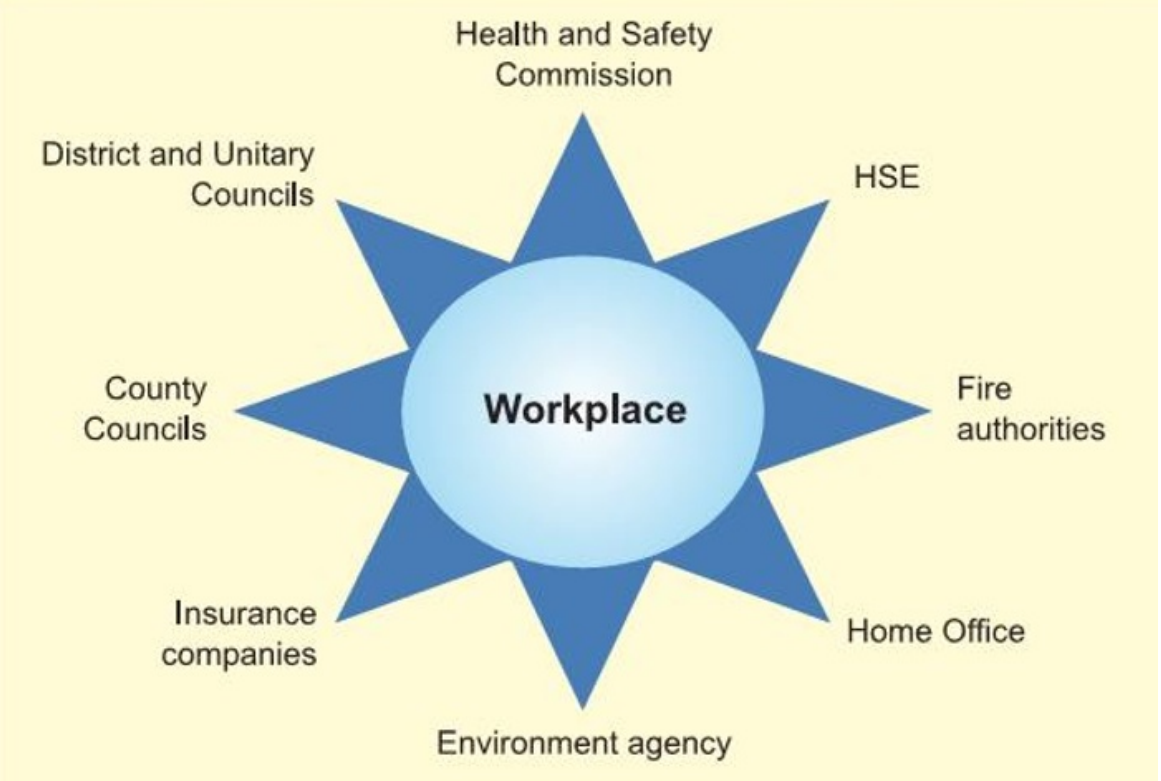

Fig. 1. The main external agencies that impact on the workspace.

Several judgments have established that employers owe a duty of care to each of their employees. This duty cannot be assigned to others, even if a consultant is employed to advice on health and safety matters or if the employees are sub-contracted to work with another employer. These duties may be sub-divided into four groups. Employers must:

$\checkmark \quad$ provide a safe place of work;

$\checkmark \quad$ provide safe plant and equipment;

$\checkmark \quad$ provide a safe system of work;

$\checkmark \quad$ provide safe and competent fellow employees.

The first introduction of an EU Directive into UK Health and Safety law occurred on 1 January 1993 when a Framework Directive on Health and Safety management and five daughter directives were introduced using powers contained in the Health and Safety at Work Act 1974. These directives, known as the European Six Pack, covered the following areas [6]:

$\checkmark \quad$ Management of Health and Safety at Work;

$\checkmark$ Provision and Use of Work Equipment;

$\checkmark$ Manual Handling;

$\checkmark$ Personal Protective Equipment;

$\checkmark$ Display Screen Equipment. 


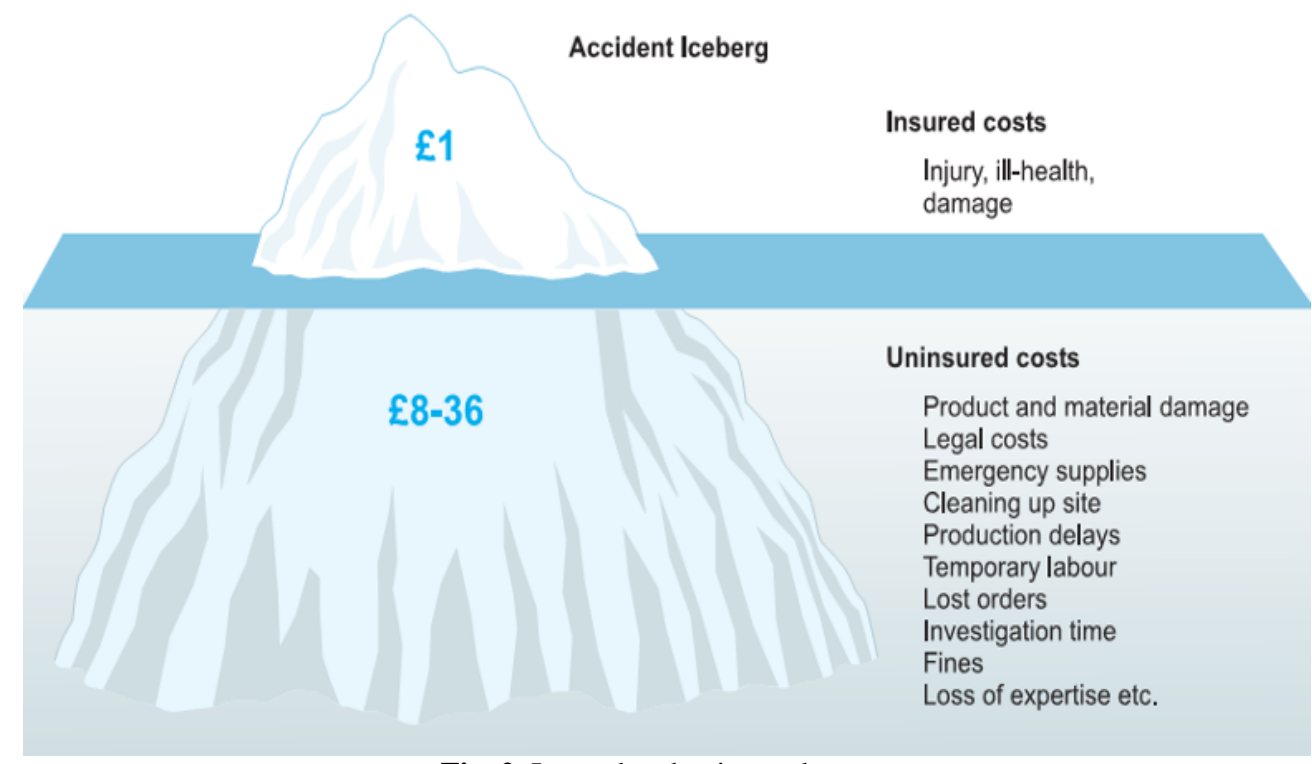

Fig. 2. Insured and uninsured costs.

Proportion of the risk and hazard during the construction period can be calculated as accident iceberg (Fig.2). While insured costs only a tiny percent of the building project and uninsured costs are really huge amount of money with compensation in account of the project holder. If we calculate malty-stored construction site damage and unexpected expenditures are extremely budget cut money [7].

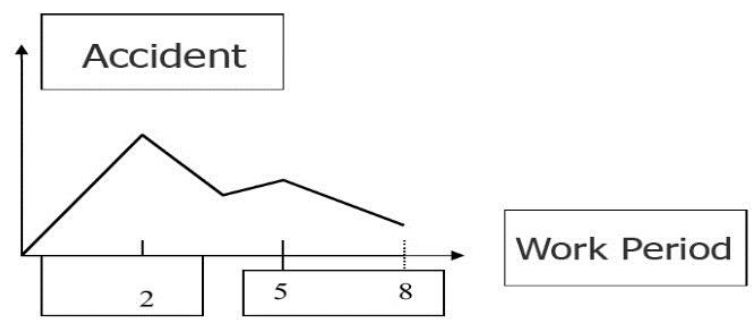

Fig. 3. Accruing accidents during working hours.

Accident level of the employees during working hours at construction site is the most hazards dynamic can be occurred. So, initial cause of injures or near misses could have been happen first two hours due to leak of concentration to workstation or workplaces (Fig.3). And the next part of the work time it reducing while after five hours it is rising again because of the tea brake and going down the rate of the expected accidents.

For both development and implementation of an HSMS to be successful, effective, and efficient, it needs to be based on a formal structure of defined elements. A successful HSMS includes but is not limited to the following seven elements [7]:

$\checkmark$ Management involvement and commitment;

$\checkmark$ Hazard identification and assessment;

$\checkmark$ Hazard control;

$\checkmark$ Emergency response; 
$\checkmark$ Incident reporting and investigation.

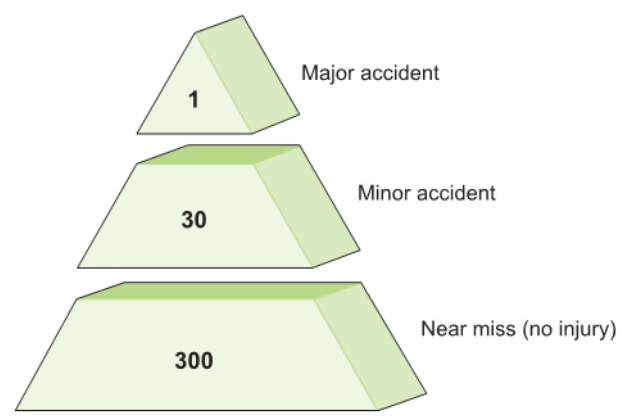

Fig. 4. Heinrich's accidents/incidents ratio.

Ratio of accident level at construction is one of the next problems of the research. It is easily seen from the picture top level indicates fatal death rate, and in the middle some injures with serious pains and the last portion of the given picture is presents very tiny injures with low level of pain or hazard at site (Fig. 4).

As for the Health and Safety regulations hazardous working conditions are the conditions under which an employee is exposed to harmful and (or) hazardous production factors, the levels of exposure of which during the working day or shift may pose a hazard to life, and the consequences may lead to the development of an occupational safety during the period of employment. Table 1 shows that level and types of the hazard during the work places [8].

Table 1. Level of hazard at work conditions.

\begin{tabular}{|l|l|l|l|}
\hline \multicolumn{1}{|c|}{ Likelihood } & \multicolumn{3}{c|}{ Severity } \\
\hline & Slight 1 & Serious 2 & Major 3 \\
\hline Low 1 & Low 1 & Low 2 & Medium 3 \\
\hline Medium 2 & Low 2 & Medium 4 & High 6 \\
\hline High 3 & Medium 3 & High 6 & High 9 \\
\hline
\end{tabular}

Thus: 6 - 9 High risk, 3 - 4 Medium risk, 1 - 2 Low risk level at working area [9].

Human failures in health and safety are either classified as errors or violations. An error is an unintentional deviation from an accepted standard, while a violation is a deliberate deviation from the standard. Human errors fall into three groups - slips, lapses and mistakes, which can be further sub-divided into rule-based and knowledge-based mistakes. Slips and lapses these are very similar in that they are caused by a momentary memory loss often due to lack of attention or loss of concentration [6]. 


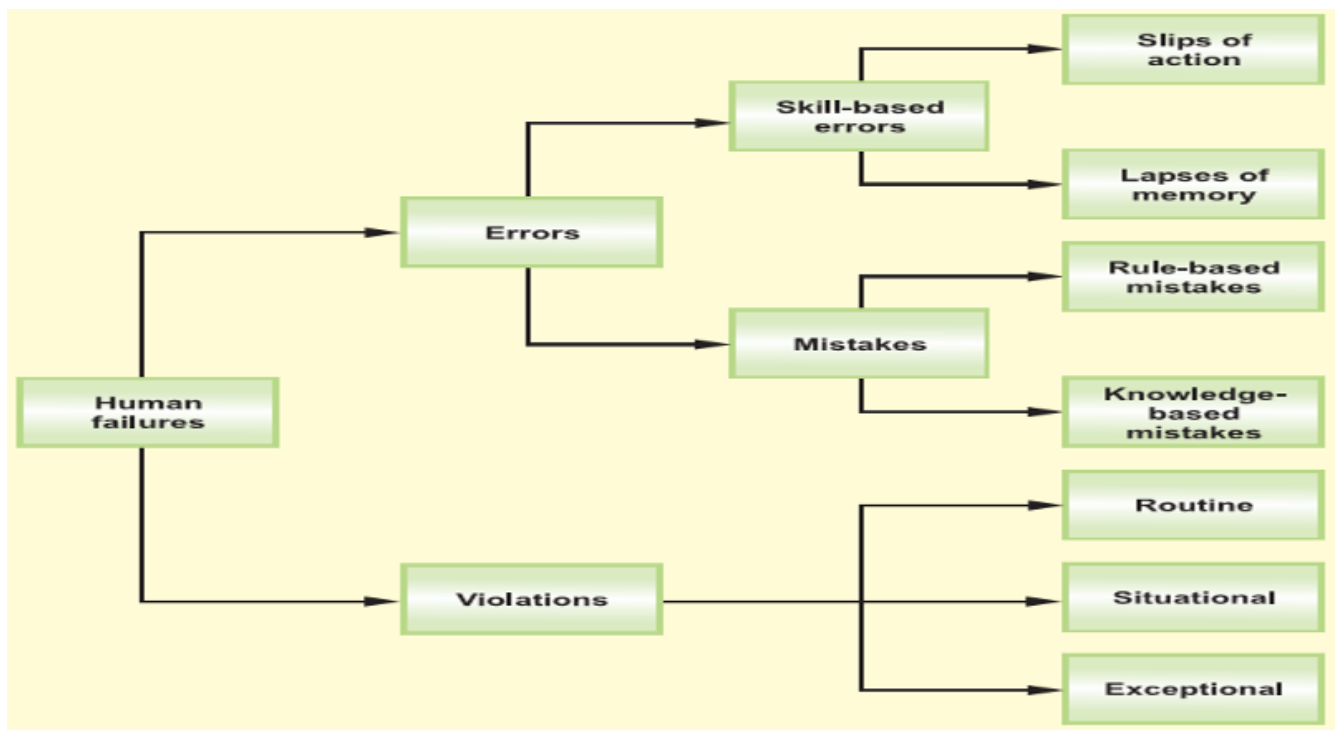

Fig. 5. Types of human failure at work.

If we analyze the accident rate of UK it is clear indicated current statistics of construction accident rate between 2017-2018 (Tab.2). It is really related with human factor which causes hazard at work process and get involved with the same problem of UK construction sector employee's at site [11].

Table 2. Key figures for Health and safety statistics, UK (2017/18).

\begin{tabular}{|l|l|}
\hline 1. & 1.4 million working people suffering from a work-related illness \\
\hline 2. & 2,595 mesothelioma deaths due to past asbestos exposures (2016) \\
\hline 3. & 144 workers killed at work \\
\hline 4. & 555,000 injuries occurred at work according to the Labour Force Survey \\
\hline 5. & 71,062 injuries to employees reported under RIDDOR \\
\hline 6. & 30.7 million working days lost due to work-related illness and workplace injury \\
\hline 7. & $\begin{array}{l}£ 15 \text { billion estimated cost of injuries and ill health from current working conditions } \\
(2016 / 17)\end{array}$ \\
\hline
\end{tabular}

\section{Results}

For the improving industrial safety examination and accreditation system, as well as the improving safety facilities in construction sector Decree of the President of the Republic of Uzbekistan dated December 12, 2018, N PP-4058 was adopted. According to the Act the State Committee for Industrial Safety is a competent public authority responsible for the implementation and monitoring of a single state policy in the field of nuclear and nuclear technology, as well as for the safety of hazardous industrial facilities; The State Committee for Industrial Safety is a part of the Cabinet of Ministers of the Republic of Uzbekistan in the complex of mining and construction industries [13].

Market leaders in every industry are increasing their grip on the chain of supply. They do so by monitoring rather than managing, and also by working more closely with suppliers. The result of this may be that suppliers or contractors are absorbed into the culture of the dominant firm, while avoiding the costs and liabilities of actual management. Self-employed workers can ensure their rights through this chain for unexpected injures and 
hazard causes.

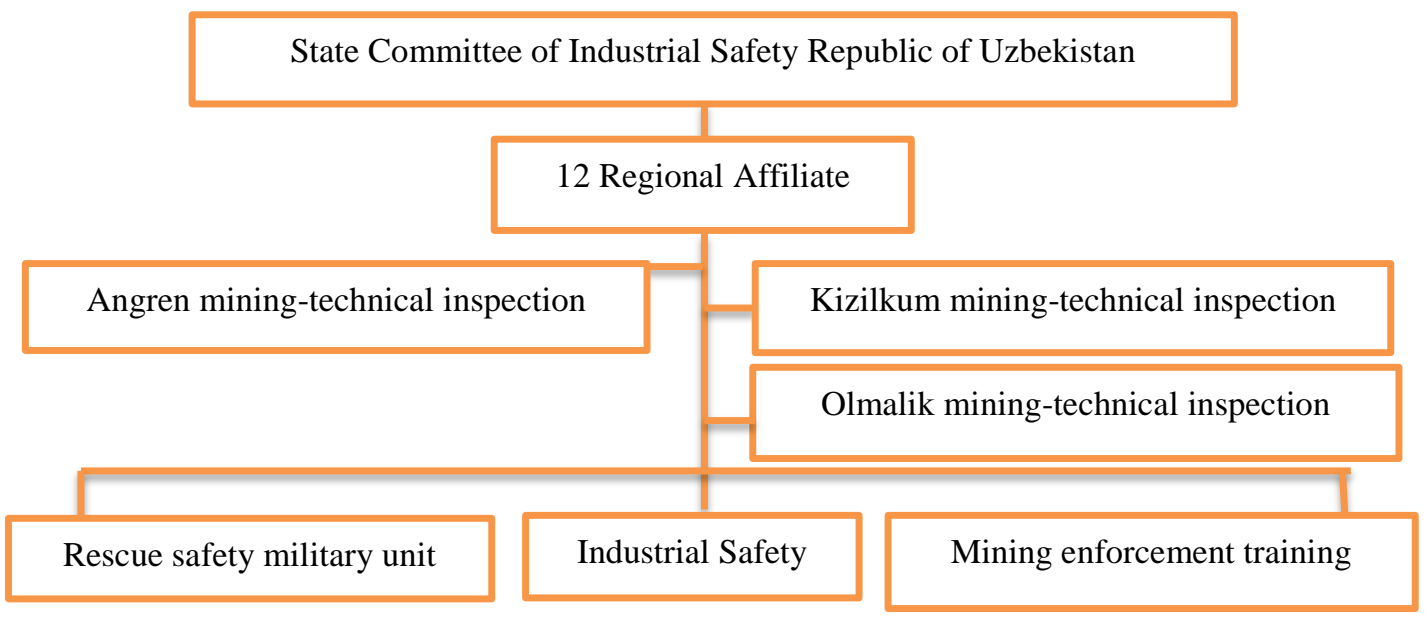

Fig. 6. Organizational Structure of Industrial Safety State Committee of the Republic of Uzbekistan.

In May of this year, the structure of the State Architecture and Construction Committee has radically changed and new tasks have been set. Territorial divisions of the Committee have been expanded with additional staff units. In particular, in Uzashakhsozlik in 11 regions and in the city of Samarkand, the Tashkent Bashplan project institute, as well as 26 leading project organizations in 13 regions were opened. Tashkent and Samarkand architectural and construction institutes and 14 construction professional colleges [14].

Under the targeted government programs, as well as during the visits of the head of our state to the regions, a number of social objects are being built on the ground. In particular, on the initiative of the President Islam Karimov, the modern international business center "Tashkent-city" is being built in the area between Tashkent, Furkat, Navoi and Olmazor streets. Samarkand-city center is being built in Samarkand on the basis of similar concept.

\section{Discussion}

This paper is a modest contribution to the ongoing discussions about current development scale of the construction industry in Uzbekistan. In our paper, the focus of attention was decreasing accident rate at construction sites via application of high standard of Health and Safety Regulations. This study shows volume of completed construction works for January-June of this year amounted to 24324.5 billion sums in Uzbekistan. The growth rate to the corresponding period of the previous year was $107.0 \%$. The volume of construction work performed by large contractor organizations, amounted to 7414.7 billion sums [15]. 


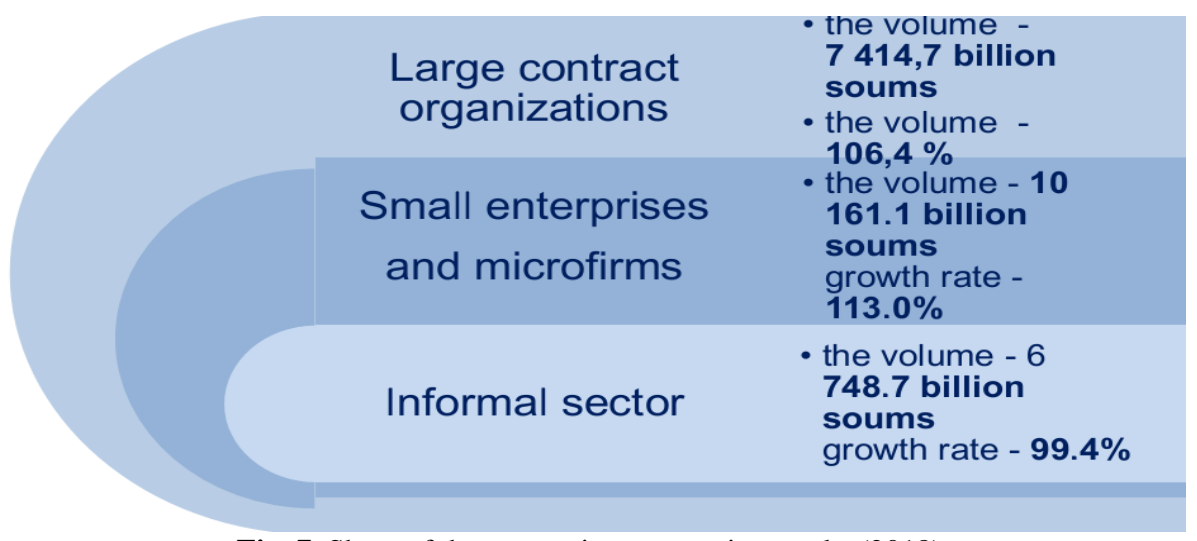

Fig. 7. Share of the sectors in construction works (2018).

This statistical data demonstrates that the volume of construction work performed by small enterprises and small firms amounted to 10161.1 billion sums, (Fig.7) or $41.8 \%$ of the total volume of construction works, the growth rate $-113.0 \%$. The share of the informal sector was $27.7 \%$, or 6748.7 billion sums, growth rate $-99.4 \%$.

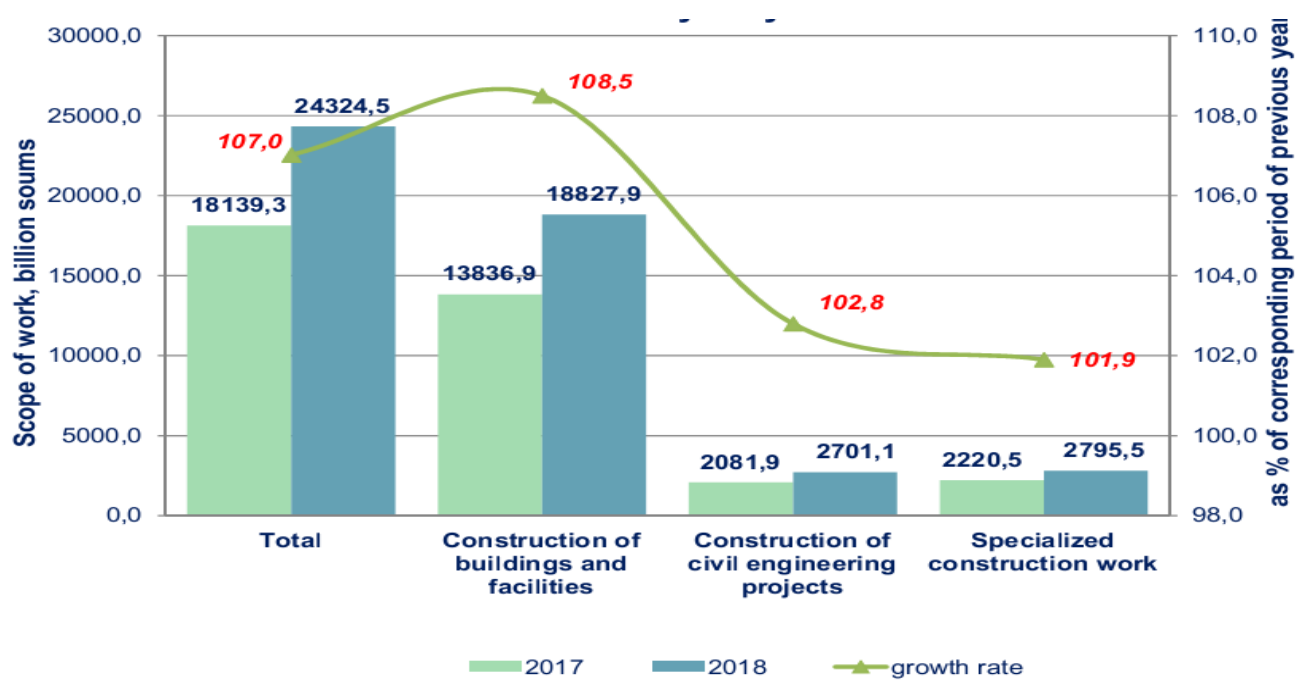

Fig. 8. Construction work by type of activity (January-July 2018).

The paper has presented several solutions to the main part of construction works by types of economic activity was carried out due to the construction of residential buildings and non-residential premises. Their share in the total volume of construction works was $77.4 \%$ and, compared to the same period last year, increased by $1.1 \%$ (Fig.8). The share in the volume of construction work for this type of economic activity, such as the construction of civilian facilities, was $11.1 \%$ and, compared to the same period last year, decreased by $0.4 \%$. The share of specialized construction works was $11.5 \%$ and, compared to the same period last year, decreased by $0.7 \%$. 


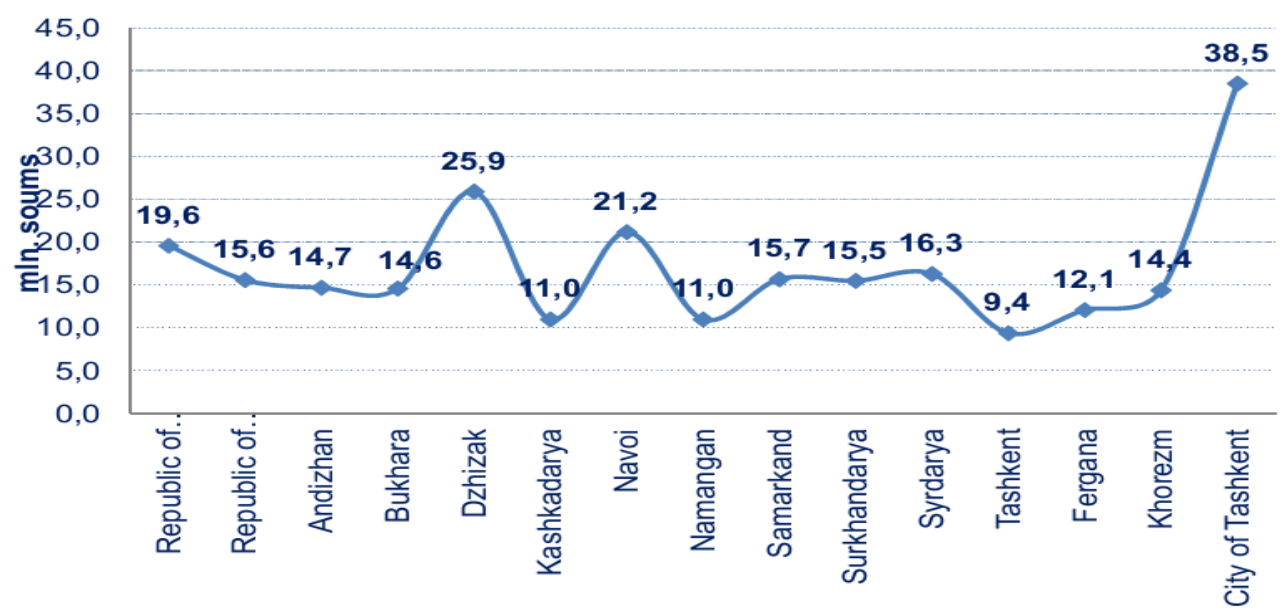

Fig. 9. Construction work for one employed in construction.

The originality of our solution lies in the fact that in the Tashkent region, one employee engaged in construction accounts for 9.4 million sums volume of construction works, which is the lowest in the Republic of Uzbekistan. Due to low income of construction industry it is hardly implement H\&S Regulation at site. City of Tashkent is the highest amount of payable money with the 38.5 million sums. In spite of this factor it is still stays unsolved problem in Tashkent construction sites.

This paper presents a pilot study to find the answer to promote safe work conditions in Uzbekistan construction industry dealing with the UK experience. According to the above analyses there are lots of construction projects had been built and new progresses of them are under construction nowadays. Our observations that analyses of modern theories and practice are not new in world construction sector but application of transition period economies such as Uzbekistan plays great role for social and economic effectiveness in the country. Due to human factor work duties are growing extremely risk and hazard level as well rising up in Uzbekistan too. From my own experience in the UK as a health and safety instructor at SCANSKA, OD Projects, many theoretical database should be upgraded and optimize for high risk assessment in sites of Uzbekistan.

From this point of view outcomes of article are transition of international occupational health and safety standards, application of current law policies in all over the industrial sectors, advantage and priorities of the UK standard comparison implementation offered. Systematical structure of Industrial Safety Committee of Uzbekistan regulation and enforcement policies will be enriched with the gap between OSH Act. Only one other study, to our knowledge, has come up with new approaches of implementation Application of UN HASP Standard and H\&S Law of EU in Uzbekistan are exactly relevant perspectives for the country $[16,17,18]$.

This paper is a modest contribution to the ongoing discussions about technological innovation in construction sector takes care of a lot of fundamental approaches. This research made it possible to identify number of following tasks in Uzbek legislation at major construction field's cooperation with the Industrial Safety Committee and Ministry of Construction as a foreign experience implementation in long term perspectives:

a) interactions between UK standard and national system solution;

b) interactions between government and international organizations;

c) interactions between public and contractors;

d) interactions between contractors construction project management;

e) interactions between inspectors and the site management; 
f) interactions between contractors and suppliers;

g) interactions between inspectors and workers $[19,20]$.

\section{Conclusions}

Taking into all account and we can come conclusion that best working condition in any industrial sectors are really relevant problem in Uzbekistan. Developed countries experiences show that annual accident rate and statistics require major advanced changes at work safety field. The observation of increased government intention to health and safety inspection puts forward recent learned problems above. This paper has clearly shown that comparison analysis shows that initial approaches of optimization innovative health and safety inspections is a modern development performance for Uzbekistan. From the statistical analysis we can find out it is beginning of the modernization of state program in cities and urban places. Civil building by public and malty stored buildings for living which building by private companies and mega projects by international organizations requires cost reduced management with the reduction of site accidents.

\section{References}

1. Construction works for January-July of 2018, the state committee of the republic of Uzbekistan on statistics annual report, p. 1-7.

2. Hafiz Zahoora, Albert P.C., Chanb Wahyudi, P.Utamaa, Ran Gaoa, A Research Framework for Investigating the Relationship between Safety Climate and Safety Performance in the Construction of Multi-storey Buildings in Pakistan. 118, p.114-251 (2015)

3. Cia World Factbook, Library publications, Uzbekistan economic sector (2018)

4. President's Appeal to the Oliy Majlis of the Republic of Uzbekistan Shavkat Mirziyoev on December 28, 2018. Appendix 2

5. Phil Hughes, Ed Ferrett. Introduction to Health and Safety in Construction. (Butterworth-Heinemann is an imprint of Elsevier, London), p.14 (2002)

6. Recommended Practices for Safety\& Health Programs in Construction, Occupational Safety and Health Administration, p.9 (2018)

7. Phil Hughes, Ed Ferrett. Introduction to Health and Safety in Construction, Second edition, Elsevier Ltd, UK, p.20 (2007)

8. Safety Handbook for Construction Site Workers, Occupational Safety and Health Branch. (Labour Department, London), p.3 (2004)

9. Scientific and Educational Material, Life Safety, Moscow, p.9 (2010)

10. Tarcisio Abreu Saurin. Safety inspections in construction sites: A systems thinking perspective, Accident Analysis and Prevention, Industrial Engineering and Transportation Department, Federal University of Rio Grande do Sul), Av. Osvaldo Aranha, 99, 5. Andar, Porto Alegre, 90035-190, Brazil (2015)

11. Health and safety made simple, The basics for your business. Health and Safety Executive. Crown copyright // www.hse.gov.uk/, First published 03/11,p 6.

12. Official web site of Health and Safety executive. http://www.hse.gov.uk/statistics/.

13. Decree of the President of the Republic of Uzbekistan on Industrial Safety Committee dated on December 12, 2018, N PP-4058. Appendix 1,2.

14. Decree of the President of the Republic of Uzbekistan on State Architecture and Construction Committee dated on November 18, 2017, PP-3256. Appendix 2.

15. Official data of the Statistic State committee. 
16. Zikriyoev A.S. Modern approaches of manufacturing competitive building materials in the construction industry. "Agricultural products Implementation of International Standards in Enhancing Competitiveness: Problems and Solutions "Republican Scientific-Practical Conference, Tashkent State University of Economics, p.4 (2018)

17. Evans D. Approved code of practice. The Organisation \& Management of Health \& Safety in Construction. (President Board of Industry, London, UK), p.16.

18. Introduction to Health and Safety Management Systems Program Development Guideline Edition, Enform, November 2011, p.9.

19. Xianguo Wua, Qian Liu, Limao Zhang, Miroslaw J. Skibniewski, Yanhong Wang. Prospective safety performance evaluation on construction sites. Accident Analysis and Prevention, 78, p.58-72 (2015)

20. Ioannis Anyfantis, Georgios Boustras, Alexandros Karageorgiou. Maintaining occupational safety and health levels during the financial crisis - A conceptual model. Safety Science, 106, p.246-254. (2018) 